\title{
Prevention of Legionnaires' Disease in the 21st Century by Advancing Science and Public Health Practice
}

\author{
Ruth L. Berkelman, Amy Pruden
}

\begin{abstract}
$\mathrm{A}^{\mathrm{d}}$ dramatic shift in emphasis by public health officials from detection, investigation, and control of outbreaks of Legionnaires' disease to primary prevention strategies is underway in the United States. Expansion of primary prevention efforts is occurring with remarkable speed and is marked by new public health guidance and policy aimed at ensuring adequacy of water systems management (1-5). Professional societies are also providing more rigorous and detailed guidance. The American Society of Heating, Refrigerating and Air-Conditioning Engineers approved an industry standard in 2015 and established minimum management requirements to reduce the risk for infection with Legionella spp., the bacteria that cause Legionnaires' disease, in building water systems ( 6 ). In 2015, the American Industrial Hygiene Society also released specific guidance on control of Legionella spp. in engineered water systems and focused on validation of water management efforts and testing water for viable Legionella spp. counts as the key tool to validate effectiveness of these efforts (7). In June 2017, the Centers for Medicaid and Medicare Services issued a requirement to reduce risk for infection with Legionella spp. in healthcare facilities (8).

This sea of change in Legionella spp. program focus in public health is occurring because of a convergence of factors. The $>5$-fold increase in cases of disease caused by Legionella spp. during 2000-2015 has mandated a substantive public health response. The increase has been widely recognized as likely to continue unabated in the absence of more effective prevention strategies. Recent large outbreaks, such as those in the Bronx, New York, USA (9), have been critical in garnering public attention and generating momentum for more robust prevention efforts. The fact that analysis by the Centers for Disease Control and Prevention indicated that only $4 \%$ of Legionnaires' disease cases were outbreak-associated has further illustrated limitations of outbreak detection and control as the primary prevention tool (1). Supported by the Alfred P. Sloan Foundation,
\end{abstract}

Author affiliations: Emory University, Atlanta, Georgia, USA

(R.L. Berkelman); Virginia Polytechnic Institute and State

University, Blacksburg, Virginia, USA (A. Pruden)

DOI: https://doi.org/10.3201/eid2311.171429 the first public health conference on Legionella spp. in 25 years identified gaping holes in our knowledge of prevention of infections with Legionella spp. and indicated the need for robust federally sponsored research (10).

Numerous factors are contributing to the increase in incidence of Legionnaires' disease. Increasing numbers of persons are at increased risk because of aging of the population, greater use of immunosuppressant drugs, and higher prevalence of comorbid conditions. Changing environmental conditions are also facilitating human exposure to aerosolized water containing Legionella spp. There is a growing dependence on heating, ventilation, and cooling systems, as well as increased complexity of indoor plumbing systems in large buildings, which have a labyrinth of water lines and features ranging from hundreds of showerheads in rooms along lengthy corridors to spas and indoor decorative fountains. Potential new sources, such as street cleaning machines reported by Valero Munoz et al. in this issue (11), continue to be identified. Inadequate maintenance of public water supplies might result in increased risk for contamination of building water systems and other water devices or equipment. Also in this issue, Lapierre et al. suggest potential new ways water systems can become contaminated; this article describes the potential for crosscontamination of cooling towers (12).

Healthcare providers play an essential role in diagnosing disease; diagnosis assists with targeting antimicrobial drug therapy, as well as playing a critical role in public health surveillance. The urine antigen test identifies only L. pneumophila serogroup 1, and its use minimizes the role of other Legionella subtypes and species (13). Respiratory diagnostic panels are increasing in number and need to include the capacity to identify all species of Legionella (14).

Ideally, a combined approach of surveillance and improved fundamental understanding of the factors triggering proliferation of Legionella spp. will inform optimal engineering design and industrial hygiene practice. Legionella spp. are known to have a symbiotic relationship with certain protozoa that graze on drinking water biofilms, and infection of these hosts can enhance virulence of the bacteria. Premise (i.e., building) plumbing can be a reservoir for pathogens such as Legionella spp., even in the presence of 
high disinfectant residuals (e.g., chlorine), and different microbes display distinct responses to various disinfectants, pipe materials, and water ages and their interactions.

Water-conserving technologies, such as reuse practices and high-volume water storage, can result in high water age, diminished protective disinfectant residuals, and degraded water quality. Low-flow velocities of certain waterconserving fixtures, now popular in many "green" buildings, might fail to adequately flush out biofilms and other particulates conducive to Legionella spp. growth. Similarly, reducing water heater temperatures may play a role in saving energy and reducing scalding, but if these benefits are found to be marginal relative to the potential to spread disease, these technologies should be reevaluated. Thus, as we as a society strive for new water- and energy-conserving building designs, the potential to stimulate Legionella spp. growth warrants serious consideration.

Respiratory pathogens other than Legionella spp., including nontuberculous mycobacteria (NTM) and Pseudomonas spp., are also found in engineered water systems. The prevalence of cases of infection with NTM is increasing dramatically and resulting in the hospitalizations of thousands of patients each year and months to years of multiple antimicrobial drug use (15). Whether current measures for prevention of Legionella spp. amplification will control other waterborne pathogens, such as NTM, is unclear. The US Environmental Protection Agency Safe Drinking Water Act, which has been in effect since the 1970s, is geared toward risk for fecal pathogens being ingested. This act does not take into account pathogens that adhere to biofilms in pipes and grow in various conditions.

Collaboration is needed across scientific disciplines and agencies to fill gaps in our collective knowledge of modern water pathogens, weaknesses in our physical water infrastructure, and inadequacies of our existing diagnostic and regulatory approaches to effectively identify and control disease risks. Legionella spp. illuminate many of the challenges posed by water pathogens in the 21 st century. With a growing national interest in a safe water supply, it is an opportune time for public health and medicine to come together with industrial hygiene, engineering, microbiology, and environmental protection to understand the problems and ensure effective risk management of Legionella spp. and other pathogens inhabiting our water systems.

This study was partially supported by the Alfred P. Sloan Foundation Microbiology of the Built Environmental Program.

Dr. Berkelman is Rollins Professor of Public Health Policy in the Department of Epidemiology, Rollins School of Public Health, Emory University, Atlanta, GA, and has joint appointments with the School of Medicine and the Emory Ethics Institute.

Her research interests include legionellosis and diseases related to the environment.
Dr. Pruden is W. Thomas Rice Professor in the Department of Civil and Environmental Engineering at Virginia Polytechnic Institute and State University, Blacksburg, VA. Her primary research interest is understanding how building plumbing design shapes the microbiome of tap water and influences the potential for Legionella and other opportunistic pathogens to proliferate.

\section{References}

1. Garrison LE, Kunz JM, Cooley LA, Moore MR, Lucas C, Schrag S, et al. Vital signs: deficiencies in environmental control identified in outbreaks of Legionnaires' disease-North America, 2000-2014. MMWR Morb Mortal Wkly Rep. 2016;65:576-84. http://dx.doi.org/10.15585/mmwr.mm6522e1

2. Soda EA, Barskey AE, Shah PP, Schrag S, Whitney CG, Arduino MJ, et al. Vital signs: health care-associated Legionnaires' disease surveillance data from 20 states and a large metropolitan area-United States, 2015. MMWR Morb Mortal Wkly Rep. 2017;66:584-9. http://dx.doi.org/10.15585/ mmwr.mm6622e1

3. Centers for Disease Control and Prevention. Developing a water management program to reduce Legionella growth and spread in buildings: a practical guide to implementing industry standards, 2016 [cited 2017 Sep 5]. https://www.cdc.gov/legionella/ WMPtoolkit

4. New York City Department of Health and Mental Hygiene. Rules of the City of New York. Title 24, Chapter 8: Cooling Towers, 2016 [cited 2017 Sep 5]. https://www1.nyc.gov/assets/doh/downloads/ pdf/notice/2016/noa-chapter8-title24.pdf

5. New York State Department of Health. Title 10, part 4 of the Official Compilation of Codes, Rules and Regulations of the State of New York, 2016 [cited 2017 Sep 5]. https://www.health.ny.gov/ regulations/nycrr/title_10/

6. American Society of $\bar{H}$ eating, Refrigerating and Air-Conditioning Engineers. Legionellosis: risk management for building water systems. ANSI/ASHRAE Standard 188. Atlanta: The Society; 2015 [cited 2017 Sep 5]. https://www.ashrae.org/resources--publications/bookstore/ ansi-ashrae-standard-188-2015-legionellosis-risk-management-forbuilding-water-systems

7. Kerbel W, Krause JD, Shelton BG, Springston J, editors. Recognition, evaluation, and control of Legionella in building water systems. Falls Church (VA): American Industrial Hygiene Association; 2015.

8. Centers for Medicaid and Medicare Services. Requirement to reduce Legionella risk in healthcare facility water systems to prevent cases and outbreaks of Legionnaires' disease (LD). Memorandum dated June 2, 2017. Baltimore, MD: US Department of Health and Human Services, Centers for Medicaid and Medicare Services, Center for Clinical Standards and Quality/ Survey and Certification Group, 2017 [cited 2017 Sep 5]. https://www.cms.gov/Medicare/Provider-Enrollment-andCertification/SurveyCertificationGenInfo/Policy-and-Memos-toStates-and-Regions.html

9. Fitzhenry R, Weiss D, Cimini D, Balter S, Boyd C, Alleyne L, et al. Legionnaires' disease outbreaks and cooling towers, New York City, New York, USA. Emerg Infect Dis. 2017; 23:1769-76.

10. From watersheds to showerheads; a workshop on Legionella research and policy. Emory University Center for Public Health Preparedness and Research. May 25-26, 2016; Atlanta, Georgia, USA [cited 2017 Sep 5]. http://www.cphpr.emory.edu/research/ legionella/workshop/index.html 
11. Valero M N, de Simon M, Galles P, Izquierdo N, Arimon J, Gonzalez R, et al. Street cleaning trucks as a potential source of exposure to Legionnella pneumophila. Emerg Infect Dis. 2017;23:1880-2.

12. Lapierre P, Nazarian E, Zhu Y, Wroblewski D, Saylors A, Passaretti T, et al. Legionnaires' disease caused by endemic strain of Legionella species, New York, New York, USA, 2015. Emerg Infect Dis. 2017;23:1784-91.

13. Vaccaro L, Izquierdo F, Magnet A, Hurtado C, Salinas MB, Gomes TS, et al. First case of Legionnaire's disease caused by Legionella anisa in Spain and the limitations on the diagnosis of Legionella non-pneumophila infections. PLoS One. 2016;11:e0159726. http://dx.doi.org/10.1371/journal.pone.0159726
14. Cristovam E, Almedia D, Caldeira D, Ferreira JJ, Marques T. Accuracy of diagnostic tests for Legionnaires' disease: a systematic review. J Med Microbiol 2017; 66:485-489.

15. Strollo SE, Adjemian J, Adjemian MK, Prevots DR. The burden of pulmonary nontuberculous mycobacterial disease in the United States. Ann Am Thorac Soc. 2015;12:1458-64. http://dx.doi.org/10.1513/AnnalsATS.201503-173OC

Address for correspondence: Ruth L. Berkelman, Department of Epidemiology, Rollins School of Public Health, Emory University, Rm 4043, Atlanta, GA 30322, USA; email: rberkel@emory.edu

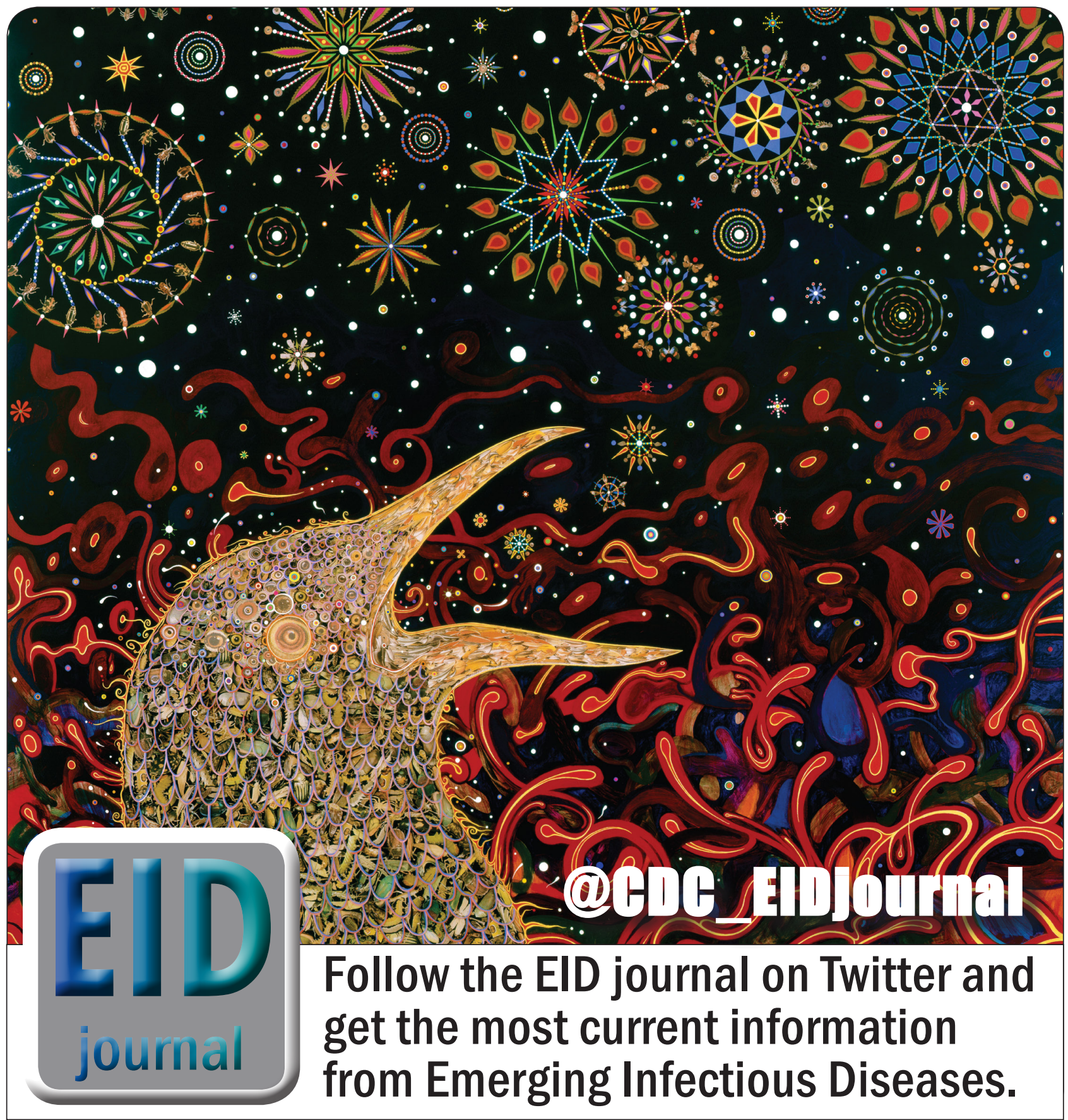

